\title{
Highlights on Recent Developments of Heterogeneous and Homogeneous Photocatalysis
}

\author{
Francesco Parrino ${ }^{1}$ and Giovanni Palmisano ${ }^{2,3, *(D)}$ \\ 1 Department of Industrial Engineering, University of Trento, Via Sommarive 9, 38123 Trento, Italy; \\ francesco.parrino@unitn.it \\ 2 Department of Chemical Engineering, Khalifa University of Science and Technology, P.O. Box 127788, \\ Abu Dhabi, UAE \\ 3 Research and Innovation on $\mathrm{CO}_{2}$ and $\mathrm{H}_{2}(\mathrm{RICH})$ Center, Khalifa University of Science and Technology, \\ P.O. Box 127788, Abu Dhabi, UAE \\ * Correspondence: giovanni.palmisano@ku.ac.ae
}

\section{check for} updates

Citation: Parrino, F.; Palmisano, G. Highlights on Recent Developments of Heterogeneous and Homogeneous Photocatalysis. Molecules 2021, 26, 23. https://dx.doi.org/10.3390/molecules 26010023

Received: 6 November 2020

Accepted: 11 November 2020

Published: 23 December 2020

Publisher's Note: MDPI stays neutral with regard to jurisdictional claims in published maps and institutional affiliations.

Copyright: () 2020 by the authors. Licensee MDPI, Basel, Switzerland. This article is an open access article distributed under the terms and conditions of the Creative Commons Attribution (CC BY) license (https: / / creativecommons.org/ licenses/by/4.0/).
Photocatalysis emerged in the last decades as a versatile technology, whose applications range from environmental remediation to hydrogen production, energy harvesting, and organic synthesis, with exciting examples also in medicine, electronics, and advanced functional materials. While homogeneous photocatalysis has a glorious and consolidated tradition, especially in the field of chemical synthesis, heterogeneous photocatalysis came into the limelight more recently, due to the appealing advantages provided by processes occurring at solid-fluid interfaces. Even if fundamental research should be never abandoned, because it is essential nourishment for applied research, photocatalysis is mature enough to demonstrate its industrial feasibility. This change in direction is especially required as far as environmental remediation is concerned, where up to now the technology transfer from lab to industry is probably the bottle neck of several processes. In this sense, we believe that novel photocatalytic materials could be defined as promising for environmental remediation only if high photocatalytic activity (possibly in the visible region) is accompanied by the required robustness, reusability, and reliability that justify industrial investments. At the same time, engineering and reactor design issues are of the utmost importance to enable scale-up of the processes and require further research. This scenario is reflected in the topics approached in the photocatalysis papers recently published in the journal Molecules. In fact, as detailed below, the majority of them deal with bare or diversely modified $\mathrm{TiO}_{2}$, which, more than any other semiconductor, combines high photoactivity for both degradation and disinfection, robustness, abundance, and low cost.

Non-metal doping has been investigated with the aim of extending the absorption ability of $\mathrm{TiO}_{2}$ toward the visible range. Carbon and nitrogen co-doping have been presented by Janus et al. [1] as an efficient approach to extend the photocatalytic activity toward the visible range. The materials have been embedded in concrete plates and provided total inactivation of Escherichia coli under simulated solar light irradiation. Pablos et al. [2] studied the Escherichia coli inactivation under UV-vis light by means of electrochemically assisted photocatalysis, by using nitrogen and fluorine co-doped $\mathrm{TiO}_{2}$ materials. Gurkan et al. [3] investigated the structural and opto-electronic features of selenium and nitrogen co-doped $\mathrm{TiO}_{2}$ and tested the materials in the photocatalytic degradation of a target pollutant (4-nitrophenol) in water. Coupling $\mathrm{TiO}_{2}$ with other semiconductors active in the visible range is another expedient to enhance the light responsive features of $\mathrm{TiO}_{2}$. For instance, Nevarez-Martinez at al. [4] synthetized nanotube arrays of $\mathrm{TiO}_{2}-\mathrm{MnO}_{2}$ by electrochemical anodization, and used them for the photocatalytic degradation of toluene in gas phase under visible light irradiation. Hong et al. [5] produced recyclable $\mathrm{TiO}_{2} / \mathrm{Fe}_{2} \mathrm{O}_{3}$ nanocomposites from ilmenite and applied these materials for the degradation of Rhodamine $\mathrm{B}$ under visible and solar light irradiation. A review has been published on the role of $\mathrm{TiO}_{2}$ coupled with carbon materials, such as carbon nanotubes, graphene, and 
carbon quantum dots, in the photocatalytic degradation of three target pharmaceutical compounds [6]. Aside from $\mathrm{TiO}_{2}$, some investigations on other photoactive materials and their environmental applications have been published, even if fewer in number with respect to those on $\mathrm{TiO}_{2}$.

As abovementioned, research on scale up issues and reactor design aimed at promoting industrial exploitation of photocatalytic reactions is still required. Applications for the purification of air already found benign market acceptance and are a step forward with respect to those in liquid phase. Accordingly, Molecules published the contribution by Alfano et al. [7], reporting a methodology for the integrated design of photocatalytic reactors for air cleaning purposes from the development of intrinsic kinetic models, ultimately targeting reactor scale-up and optimization. Dumont et al. [8] described theoretical and experimental approaches for the determination of the Clean Air Delivery Rate (CADR) of photocatalytic air purifiers. Different reactor designs have been proposed in other contributions. For instance, Montalvo et al. [9] proposed a semi-pilot rotating photocatalytic reactor, and Pellegrino et al. [10] described the photocatalytic activity of a cordierite-honeycomb-supported $\mathrm{TiO}_{2}$ film in a liquid-solid photoreactor for water treatments applications.

It is worth mentioning that the combination of heterogeneous photocatalysis with other advanced oxidation processes or physical methods [11,12] is a viable and competitive tool to boost industrial appeal. In fact, synergetic effects could reduce the drawbacks of the contributing single technologies, simultaneously increasing the efficiency of the whole process. To this aim, Beltran and Rey [13] published a review in Molecules on solar or visible light photocatalytic ozonation by discussing on the effects of the main intervening parameters.

A completely different situation holds when photocatalysis is used for the synthesis of high-value-added compounds as an alternative to traditional synthetic paths. Homogeneous photocatalysis is a well-established strategy for organic synthesis, as confirmed by the fact that the majority of the papers published in Molecules on photocatalytic synthetic processes occur in the presence of organometallic complexes in a homogeneous phase. Protti et al. [14] exploited the acidity of photo-excited molecules to drive C-C and C-S bond formation processes by providing a viable alternative to the use of aggressive acids and harsh conditions. Iron-based organometallic complexes have been used under visible light irradiation to reduce $\mathrm{CO}_{2}$ into $\mathrm{CO}$ [15], ruthenium complexes bearing pyridine-quinoline or terpyridine ligands were utilized in the atom transfer radical addition of haloalkanes to olefins [16], while the effects of some reaction parameters were investigated for the photodimerization of 2-anthracenecarboxylate catalyzed by platinum (II) complexes [17]. A comprehensive review on photocatalytic difluoromethylation reactions of aromatic compounds and aliphatic multiple $\mathrm{C}-\mathrm{C}$ bonds in the presence of organometallic compounds have been also published [18].

On the other hand, heterogeneous photocatalysis for synthetic purposes is less represented. In fact, only one paper has been published on the selective partial oxidation of cyclohexane [19]. This fact reflects a general mistrust with respect to the potentiality of heterogeneous photocatalysis for the synthesis of relevant industrial compounds. Production of raw materials [20], naturally occurring compounds [21], or valuable intermediates [22] in good to excellent yields have been accomplished, but correspondent advancements in the engineering of the processes are still required. Moreover, some of the contributions only report chromatographic or spectroscopic evidence of the formed products, without any concern on purification and separation, at least on a gram scale. In our opinion, advancements in membrane reactors [23] could support the development of this intriguing field, which offers competitive alternatives to classical synthetic protocols under milder conditions and in fulfilment of the green chemistry principles.

Funding: This research received no external funding.

Conflicts of Interest: The authors declare no conflict of interest. 


\section{References}

1. Janus, M.; Kusiak-Nejman, E.; Rokicka-Konieczna, P.; Markowska-Szczupak, A.; Zajac, K.; Morawski, A.W. Bacterial Inactivation on Concrete Plates Loaded with Modified $\mathrm{TiO}_{2}$ Photocatalysts under Visible Light Irradiation. Molecules 2019, 24, 26. [CrossRef] [PubMed]

2. Pablos, C.; Marugán, J.; Van Grieken, R.; Dunlop, P.S.; Hamilton, J.W.; Dionysiou, D.D.; Byrne, J.A. Electrochemical Enhancement of Photocatalytic Disinfection on Aligned $\mathrm{TiO}_{2}$ and Nitrogen Doped $\mathrm{TiO}_{2}$ Nanotubes. Molecules 2017, 22, 704. [CrossRef] [PubMed]

3. Gurkan, Y.Y.; Kasapbasi, E.; Turkten, N.; Cinar, Z. Influence of Se/N Codoping on the Structural, Optical, Electronic and Photocatalytic Properties of $\mathrm{TiO}_{2}$. Molecules 2017, 22, 414. [CrossRef] [PubMed]

4. Nevárez-Martínez, M.C.; Mazierski, P.; Kobylański, M.P.; Szczepańska, G.; Trykowski, G.; Malankowska, A.; Kozak, M.; EspinozaMontero, P.J.; Zaleska-Medynska, A. Growth, Structure, and Photocatalytic Properties of Hierarchical $\mathrm{V}_{2} \mathrm{O}_{5}-\mathrm{TiO}_{2} \mathrm{Nanotube}$ Arrays Obtained from the One-step Anodic Oxidation of Ti-V Alloys. Molecules 2017, 22, 580. [CrossRef] [PubMed]

5. Hong, T.; Mao, J.; Tao, F.; Lan, M. Recyclable Magnetic Titania Nanocomposite from Ilmenite with Enhanced Photocatalytic Activity. Molecules 2017, 22, 2044. [CrossRef] [PubMed]

6. Mestre, A.S.; Carvalho, A.P. Photocatalytic Degradation of Pharmaceuticals Carbamazepine, Diclofenac, and Sulfamethoxazole by Semiconductor and Carbon Materials: A Review. Molecules 2019, 24, 3702. [CrossRef]

7. Passalía, C.; Alfano, O.M.; Brandi, R.J. Integral Design Methodology of Photocatalytic Reactors for Air Pollution Remediation. Molecules 2017, 22, 945. [CrossRef] [PubMed]

8. Héquet, V.; Batault, F.; Raillard, C.; Thévenet, F.; Le Coq, L.; Dumont, É. Determination of the Clean Air Delivery Rate (CADR) of Photocatalytic Oxidation (PCO) Purifiers for Indoor Air Pollutants Using a Closed-Loop Reactor Part II: Experimental Results. Molecules 2017, 22, 408. [CrossRef]

9. Montalvo-Romero, C.; Aguilar-Ucán, C.; Alcocer-Dela hoz, R.; Ramirez-Elias, M.; Cordova-Quiroz, V. A Semi-Pilot Photocatalytic Rotating Reactor (RFR) with Supported $\mathrm{TiO}_{2} / \mathrm{Ag}$ Catalysts for Water Treatment. Molecules 2018, 23, 224. [CrossRef] [PubMed]

10. Pellegrino, F.; De Bellis, N.; Ferraris, F.; Prozzi, M.; Zangirolami, M.; Petriglieri, J.R.; Schiavi, I.; Bianco-Prevot, A.; Maurino, V. Evaluation of the Photocatalytic Activity of a Cordierite-Honeycomb-Supported $\mathrm{TiO}_{2}$ Film with a Liquid-Solid Photoreactor. Molecules 2019, 24, 4499. [CrossRef]

11. Toledano Garcia, D.; Ozer, L.Y.; Parrino, F.; Ahmed, M.; Brudecki, G.P.; Hasan, S.W.; Palmisano, G. Photocatalytic ozonation under visible light for the remediation of water effluents and its integration with an electro-membrane bioreactor. Chemosphere 2018, 209, 534-541. [CrossRef] [PubMed]

12. Cataldo, S.; Iannì, A.; Loddo, V.; Mirenda, E.; Palmisano, L.; Parrino, F.; Piazzese, D. Combination of advanced oxidation processes and active carbons adsorption for the treatment of simulated saline wastewater. Sep. Purif. Technol. 2016, 171, 101-111. [CrossRef]

13. Beltrán, F.J.; Rey, A. Solar or UVA-Visible Photocatalytic Ozonation of Water Contaminants. Molecules 2017, 22, 1177. [CrossRef] [PubMed]

14. Strada, A.; Fredditori, M.; Zanoni, G.; Protti, S. Acid Catalyzed Formation of C-C and C-S Bonds via Excited State Proton Transfer. Molecules 2019, 24, 1318. [CrossRef] [PubMed]

15. Fu, Z.-C.; Mi, C.; Sun, Y.; Yang, Z.; Xu, Q.-Q.; Fu, W.-F. An Unexpected Iron (II)-Based Homogeneous Catalytic System for Highly Efficient $\mathrm{CO}_{2}$-to-CO Conversion under Visible-Light Irradiation. Molecules 2019, 24, 1878. [CrossRef] [PubMed]

16. Voutyritsa, E.; Triandafillidi, I.; Tzouras, N.V.; Nikitas, N.F.; Pefkianakis, E.K.; Vougioukalakis, G.C.; Kokotos, C.G. Photocatalytic Atom Transfer Radical Addition to Olefins Utilizing Novel Photocatalysts. Molecules 2019, 24, 1644. [CrossRef]

17. Rao, M.; Wu, W.; Yang, C. Effects of Temperature and Host Concentration on the Supramolecular Enantiodifferentiating [4 + 4] Photodimerization of 2-Anthracenecarboxylate through Triplet-Triplet Annihilation Catalyzed by Pt-Modified Cyclodextrins. Molecules 2019, 24, 1502. [CrossRef]

18. Barata-Vallejo, S.; Postigo, A. Photocatalytic Difluoromethylation Reactions of Aromatic Compounds and Aliphatic Multiple C-C Bonds. Molecules 2019, 24, 4483. [CrossRef]

19. Henríquez, A.; Melin, V.; Moreno, N.; Mansilla, H.D.; Contreras, D. Optimization of Cyclohexanol and Cyclohexanone Yield in the Photocatalytic Oxofunctionalization of Cyclohexane over Degussa P-25 under Visible Light. Molecules 2019, 24, 2244. [CrossRef]

20. Parrino, F.; Camera-Roda, G.; Loddo, V.; Palmisano, L. Elemental Bromine Production by $\mathrm{TiO}_{2}$ Photocatalysis and/or Ozonation. Angew. Chem. (Int. Engl.) 2016, 55, 10391-10395. [CrossRef]

21. Ciriminna, R.; Parrino, F.; De Pasquale, C.; Palmisano, L.; Pagliaro, M. Photocatalytic partial oxidation of limonene to 1,2 limonene oxide. Chem. Commun. 2018, 54, 1008-1011. [CrossRef] [PubMed]

22. Bellardita, M.; Loddo, V.; Mele, A.; Panzeri, W.; Parrino, F.; Pibiri, I.; Palmisano, L. Photocatalysis in dimethyl carbonate green solvent: Degradation and partial oxidation of phenanthrene on supported $\mathrm{TiO}_{2}$. RSC Adv. 2014, 4, 40859-40864. [CrossRef]

23. Camera-Roda, G.; Loddo, V.; Palmisano, L.; Parrino, F.; Santarelli, F. Process intensification in a photocatalytic membrane reactor: Analysis of the techniques to integrate reaction and separation. Chem. Eng. J. 2017, 310, 352-359. [CrossRef] 